\title{
INSTRUCCIONES PARA ENCONTRAR A DIOS
}

\author{
Isabel Zapata*
}

Toda puerta conduce a Él, todo paso nos aleja más.

\section{I}

Me inquieta lo que se esconde detrás de los espejos. Intento introducirme en ellos en busca de la fórmula que determina el vuelo de los ángeles, de un elixir que me enseñe a amar sin condiciones, de cualquier sustancia que cure las heridas de vidas pasadas.

Necesito aprender a interpretar los signos divinos que aparecen por momentos dibujados en mi cuerpo, o en las confusas palabras de algún personaje onírico. Sospecho que hay ahí un mensaje urgente para mí, la clave definitiva para descifrar a Dios.

\section{II}

Encuentro a Dios en la cruz que señala el tesoro escondido entre mis pechos. Él es el primer trazo de la primera letra de la primera palabra escrita. Es también esta letra que escribo ahora. Dios está en la irreverencia del más maldito de los poetas, en la bondad del más virtuoso de

* Alumna de Ciencia Política, ITAM. Poeta. 
DIÁLOGO DE POETAS

los hombres. En la mediocridad de cualquiera de ellos. Las especias de cocina; ése es el olor de Dios.

\section{III}

Hay una tormenta perpetuamente anunciada en mis entrañas. Despierto siempre temiendo que sea el día. A diario llueve, pero el agua apenas me moja los talones. 